\title{
Effect on the Difference in Distances between GPR Antennas on Data Quality using Modeling
}

\author{
Gamil Alsharahi, Majid Rochdi, Ahmed Faize, Mohammed Hamdaoui
}

\begin{abstract}
The aim of this work is studying the influence the distance between the antenna of ground penetrating radar (GPR) on quality of the signals and ability to detection the targets buried. We used for the modelling of behavior the signal by development the code on GprMax2d program. The distances different has used in this work and frequencies different. In this work we will simulate the operation of GPR using the common source point mode where the source is fixed and the receiver moved along the inspection profile for three values of the distance between the antennas. The simulations were performed for three different frequencies.
\end{abstract}

Keywords: Ground Penetrating Radar (GPR), Modeling, monostatic, quality, singlas.

\section{INTRODUCTION}

The Ground Penetration Radar (GPR) is a very effective tool to detect and identify objects buried under the ground; it is also effective to map structures and features buried in the ground. The GPR works by emitting an electromagnetic wave into the ground and recording the echoes that result from subsurface objects. In the case of monostatic configuration, the GPR use a single antenna to transmit and receive, and for the bistatic configuration, the transmitter and the receivers are separated from each other spatially. The main advantages of the bistatic configuration is the possibility to imagine different scenarios to record the GPR data. [1], [2].

The GPR data are affected by noise and interference caused by various sources. For example, boulders, animal burrows, tree roots, and other phenomena can cause unwanted reflections or scattering phenomena. In the case of urban environment, sources of noise can include reflections from nearby vehicles, buildings, fences, power lines, and trees.

The noise on GPR data can also cause by radiating signals from wireless systems (cell phones...). The effect of this noise GPR images is to blur the details, and complicates reconnaissance of the useful information. [3], [4], [5].

Revised Manuscript Received on April 13, 2020.

* Correspondence Author

Gamil Alsharahi*, Department of Physics, Faculty of Polydisciplinary, Mohammed First University, Morocco. Email: alsharahigamil@gmail.com

Majid Rochdi, Department of Physics, Faculty of Polydisciplinary, Mohammed First University, Morocco. Email: m.rochdi@ump.ac.ma

Ahmed faize, Department of Physics, Faculty of Polydisciplinary, Mohammed First University, Morocco. Email: ahmedfaize6@hotmail.com

Mohammed Hamdaoui, Department of Physics, Faculty of Polydisciplinary, Mohammed First University, Morocco. Email: hamdawimohammedpc@gmail.com

(C) The Authors. Published by Blue Eyes Intelligence Engineering and Sciences Publication (BEIESP). This is an open access article under the CC BY-NC-ND license (http://creativecommons.org/licenses/by-nc-nd/4.0/)
In this work, we focus on the Electromagnetic coupling between the two antennas in the case of bistatic configuration. Indeed, the radar detects a reflection wave from an object by the receiver antenna, on the other hand the receiver antenna also receives the direct wave from transmitter antenna. In the case if, the distance between the two antennas is comparable to the expected object distance, this direct wave occurs artifact image. In this paper, we study the effect of the distance on the direct coupling on a bistatic configuration [13-14].

\section{MATERIEL AND METHOD}

\section{A. Methods and theoretical background}

FDTD based for GPR modelling and simulation Maxwell's electromagnetic equations that mathematically express the relations between the fundamental electromagnetic field quantities and their dependence on their sources can be used to describe all electromagnetic phenomena. The fundamental equations are [3]: Acquisition methods have to be synchronized and all referred to the same coordinate system in order to integrate the geometric data collected by the different techniques [6], [7], [8-11].

\section{B. GprMax2d}

The "GprMax 2D /3D" is a program designed in 1996 by Antonios Giannopolos, University of York Island. Aim to a wave simulator of GPR 2D and 3D as required by using the best adapted version of the desired work. It is based on the numerical method the F.D.T.D. This software is installed on Windows and has been successfully in more cases, where need to understanding, evaluation and comparative with other software tools [9], [12].

\section{RESULTS AND DISCUSSION}

\section{A. Results obtained for $800 \mathrm{MHz}$}

\section{Distance between antennas is $30 \mathrm{~cm}$}

In the first case we simulate with a frequency of $800 \mathrm{MHz}$ the detection of two different objects one conductor and the other dielectric buried at a depth of $0.5 \mathrm{~m}$ and the distance between the two antennas is 30 cmas shown in figure 1 (a). The radargram obtained in figure 1 (b) shows two hyperboles that indicates the presence of the two objects and lines above at a depth $20 \mathrm{~cm}$ are caused by the direct wave between the two antennas.

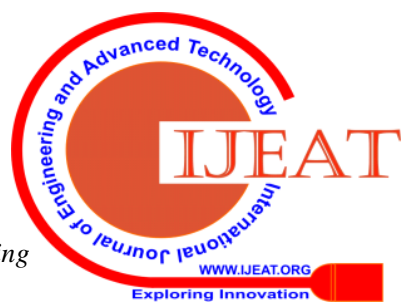


We can also notice the presence of the direct wave on the time evolution of the GPR waves on figure 1 (c). These results show that this phenomenon can hide an object near to the surface. [11].

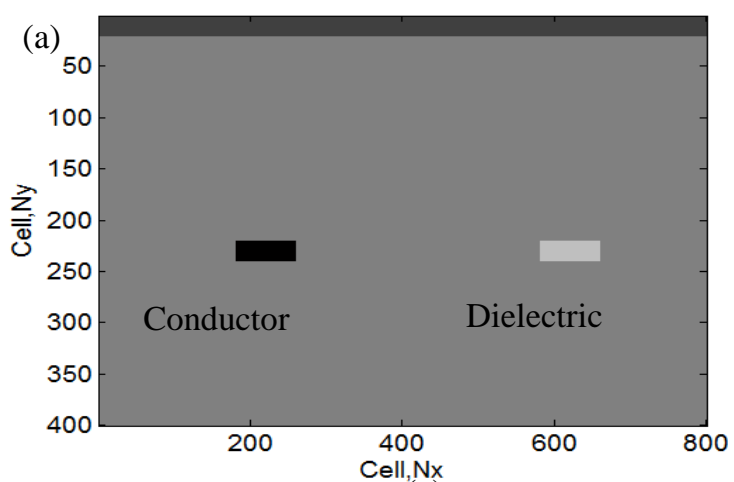

(a)

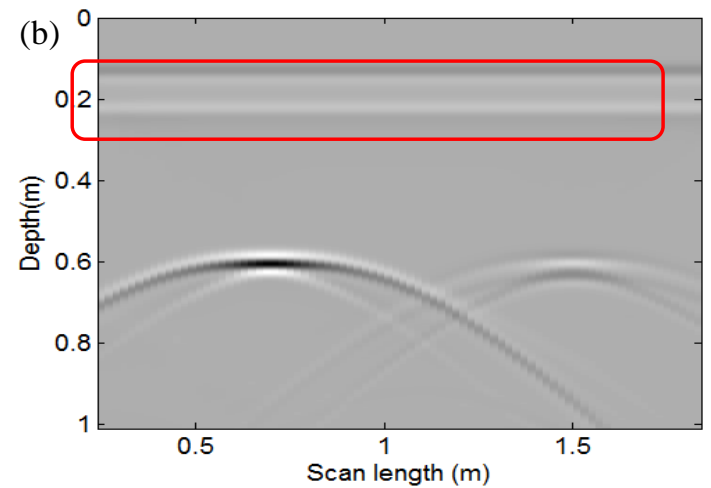

(c)

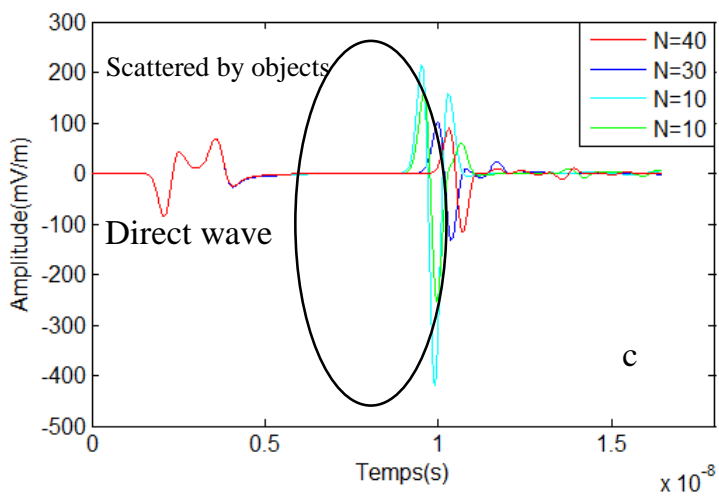

Fig. 1.(a) GPR simulation scenario (b) radargram (c) time evolution of GPR waves.

\section{Distance between antennas is $20 \mathrm{~cm}$}

We repeat the simulation for the same scenario, but in this case, we reduce the distance between the two antennas at $20 \mathrm{~cm}$. We can notice that the radargram obtained in figure 2 (a) is very similar to the first one. The only difference is the height of the horizontal lines due to the direct wave. Indeed, in the first case (when the distance is $30 \mathrm{~cm}$ ) the horizontal lines are centered round on $20 \mathrm{~cm}$ of depth, and in the second case (when the distance is $20 \mathrm{~cm}$ ) the horizontal lines are slightly above the depth of $20 \mathrm{~cm}$.
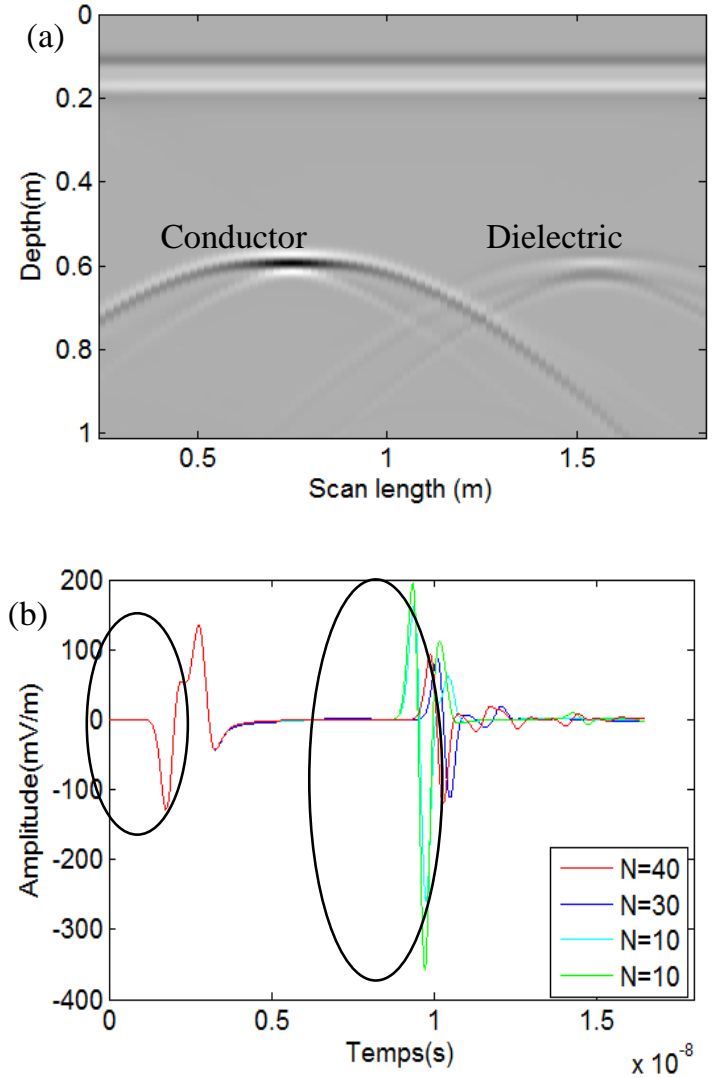

Fig. 2.(a) Radargram (b) time evolution of GPR waves.

\section{Distance between antennas is $10 \mathrm{~cm}$}

For the third scenario, we reduce the distance between the two antennas to $10 \mathrm{~cm}$. On the radargram shown in figure 3 (a), we can notice that the amplitude of the direct wave is significantly higher in this case to the two precedents cases. We can also notice that the horizontal lines are slightly above $10 \mathrm{~cm}$ of depth.

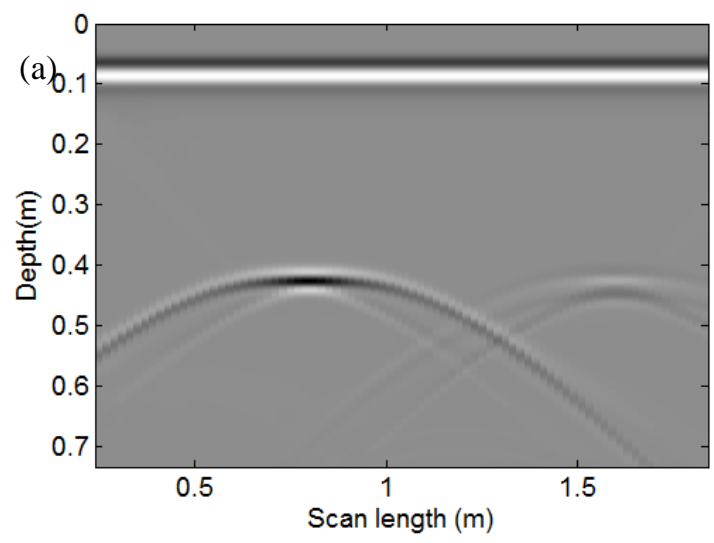

Published By:

Blue Eyes Intelligence Engineering

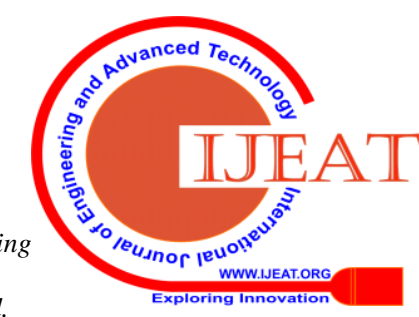


(c)

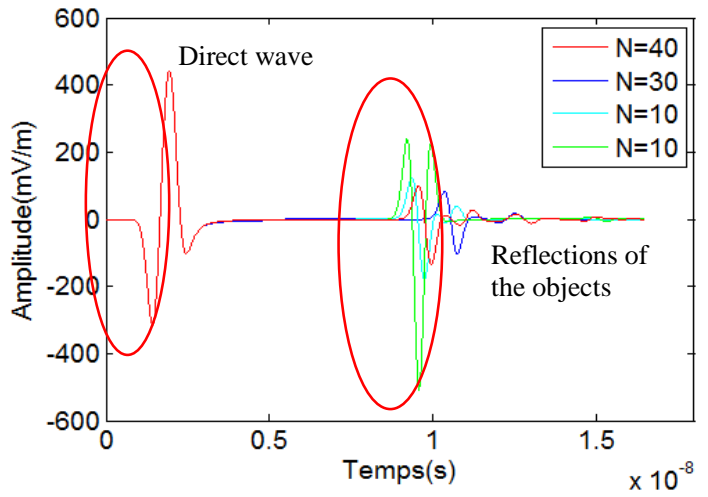

Fig. 3.(a) Radargram (b) time evolution of GPR waves.

\section{B. Results obtained for $400 \mathrm{MHz}$}

In this section, we will use a frequency of $400 \mathrm{MHz}$ for the same conditions (same objects at the same depth). The figure 4 shows the simulated results for the three distances between the two antennas. For the case when the distance between the antennas is $30 \mathrm{~cm}$ we can notice that the horizontal lines due to the direct wave appears slightly below $20 \mathrm{~cm}$ (slightly deeper that for the $\mathrm{f}=800 \mathrm{MHz}$ ).
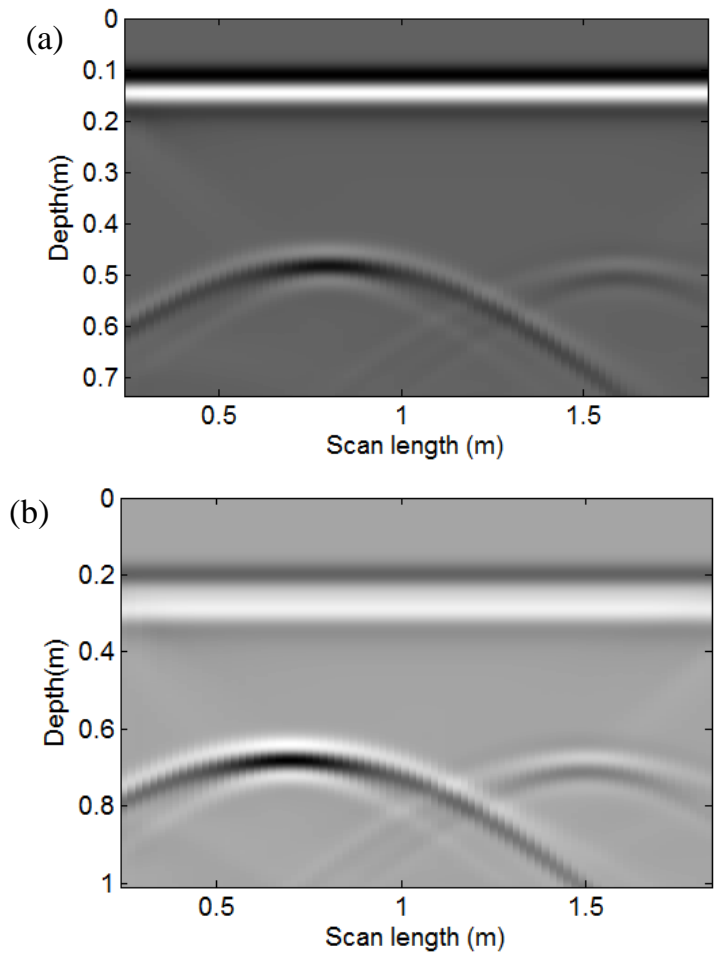

(C)

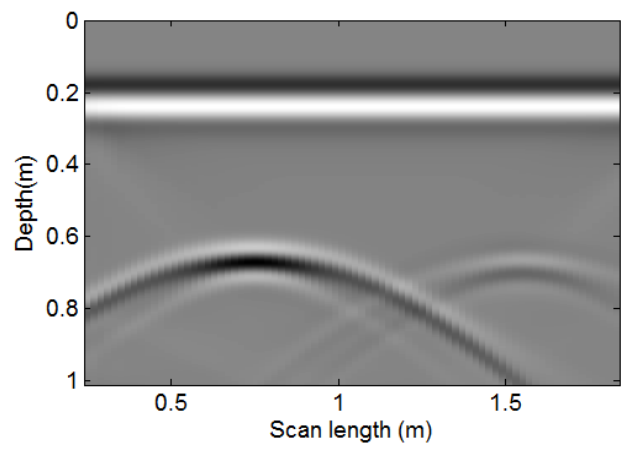

C

Fig. 4.(a) Radargram distance between antennas is $30 \mathrm{~cm}$,

(b) distance between antennas is $20 \mathrm{~cm}$, (c) distance between antennas is $10 \mathrm{~cm}$..

\section{Results obtained for $200 \mathrm{MHz}$}

For the third case we simulate the same scenario but this time at $200 \mathrm{MHz}$. We can observe on the results shown on figure 5 that the horizontal lines are deeper and most marked than the others two frequency.

(a)

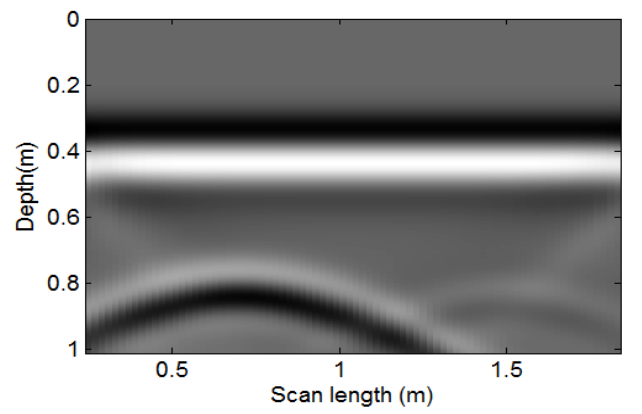

(b)

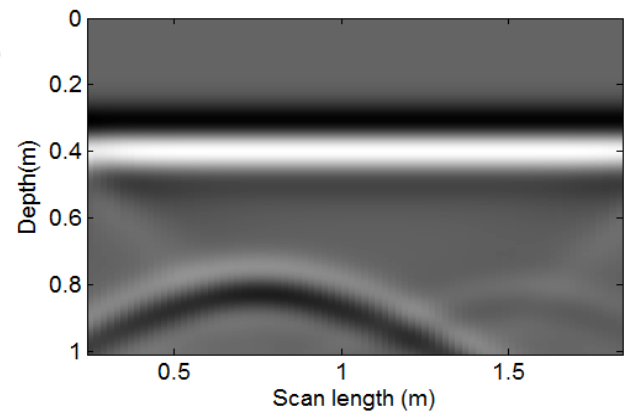

(c)

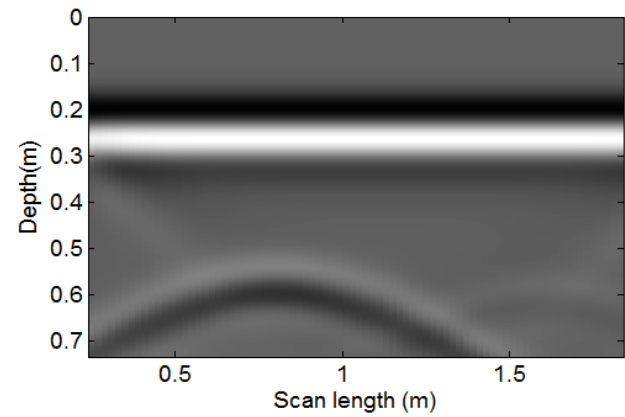

Fig. 5.Radargram (a), distance between antennas is $30 \mathrm{~cm}$ (b), distance between antennas is $20 \mathrm{~cm}$ and (c) distance between antennas is $10 \mathrm{~cm}$.

\section{CONCLUSION}

In this paper we focused on electromagnetic coupling between the two antennas in bistatic configuration. The simulated results show the effect of the direct wave traveling from the transmitting antenna toward to the receiving antenna. Indeed, for three different distance between antennas $(30 \mathrm{~cm}$, $20 \mathrm{~cm}, 10 \mathrm{~cm}$ ) we have noticed that the effect of the direct wave appears as horizontal lines in the radargram, and the depth of this lines change with distance between the antennas and it's also depend on the frequency. The simulated results show that it's important de take account the direct coupling between transmitting antenna and the receiving antenna, because it can hide objects near to the surface.

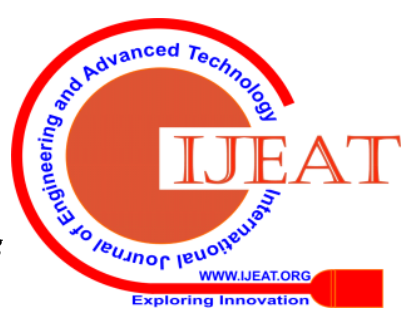




\section{REFERENCES}

1. Fernandez, MG, Gonzalez-Valdes, B., Arboleya, AA, Rodriguez-Vaqueiro, Y., Lopez, YA, Garcia, AP, \& Andres, FL-H. (2017). Validation expérimentale d'un système d'imagerie GPR. 2017 11e Conférence européenne sur les antennes et la propagation (EUCAP)

2. Kang, W., Kim, CR, Kim, JH, Park, SG, Cho, SJ, Son, JS et Kim, KW (2016). Une étude de la configuration des antennes pour les radars bistatiques pénétrant le sol. 2016 16e Conférence internationale sur les radars pénétrants au sol (GPR)

3. Li, Y., Zhao, Z., Xu, W., Liu, Z., and Wang, X. (2019). An effective FDTD model for GPR to detect the material of hard objects buried in the working soil layer. Soil and Tillage Research, 195

4. Montiel-Zafr, "A new method for eliminating GPR background noise based on the similarity of the non-neighboring region", Journal of Applied Geophysic, 2017

5. Prego, FJ, Solla, M., Puente, I., et Arias, P. (2017). Acquisition efficace des données GPR pour détecter les canalisations souterraines. NDT \& E International, 91, 22-31

6. Gamil Alsharahi, AMM .Mostapha, Abdellah Driouach and Ahmed Faize, "Modeling and resolution of simulation of ground penetration radar antennas". Journal of electromagnetic engineering and science Volume 16, Number 3, 2016, pp.182-190

7. Ghasemi, Faezeh, Sh, A., Abrishamian, M.S., 2007. A novel method for FDTD numerical GPR imaging of arbitrary shapes based on Fourier transform. NDT \& E Int. 40 (2), 140-146.

8. G. Alsharahi, "2D FDTD Simulation to Study Response of GPR Signals in Homogeneous and Inhomogeneous Mediums", International Journal on Communications Antenna and Propagation (IRECAP), vol. xx, n. x June 2010

9. Aziz, A., Setyawati, O., Rahmadwati, R., \& Bangert, A. (2018). Model Simulation of Ground Penetrating Radar using GPRMax to Detect Porang Tuber. 2018 Electrical Power, Electronics, Communications, Controls and Informatics Seminar (EECCIS).

10. H. M. Jol, "Ground Penetraing Radar : Theory and Applications," 2009, Oxford : Elsevier Sience

11. Xie, F., Wu, C. G.-W., Lai, W. W.-L., \& Sham, J. F.-C. (2018) Correction of multi-frequency GPR wave velocity with distorted hyperbolic reflections from GPR surveys of underground utilities. Tunnelling and Underground Space Technology, 76, 76-91.

12. Alsharahi, Gamil, Ahmed Faize, Carmen Maftei, and Abdellah Driouach. "GPR Application for Risks Detection in Subsurface Engineering Construction Projects." Ovidius University Annals of Constanta-Series Civil Engineering 21, no. 1 (2019): 51-58.

13. Alsharahi, G., A. Faize, M. Louzazni, A. M. M. Mostapha, M. Bayjja, and A. Driouach. "Detection of cavities and fragile areas by numerical methods and GPR application." Journal of Applied Geophysics 164 (2019): 225-236.

14. Alsharahi, Gamil, Ahmed Faize, Carmen Maftei, Mohamed Bayjja, Mohamed Louzazni, Abdellah Driouach, and Abdellatif Khamlichi. "Analysis and Modeling of GPR Signals to Detect Cavities: Case Studies in Morocco." Journal of Electromagnetic Engineering and Science 19, no. 3 (2019): 177-187.

\section{AUTHORS PROFILE}

Gamil Alsharahi was born in Amran City, Yemen, in 1979. He received aB.S. in mathematics and physics and master's degrees in telecommunication and electronics from Abdelmalek Essaadi University, Faculty of Sciences, Tetouan. He holds a $\mathrm{PhD}$ in electronics from Abdelmalek Essaadi University, Faculty of Sciences, Tetouan in December, currently he is working as a research professor at the Faculty of Interdisciplinary Nador, University of Mohamed I.

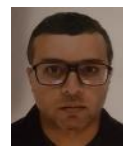

Majid ROCHDI was born in Nador, Morocco, in 1978 He received a Master of Science in Communications Engineering, and a Ph.D. in electronic from university occidental of Bretagne, Brest, France in 2011. He worked as a Temporary Assistant Professor (ATER) of the University of Technology of Compiegne from 2012 to 2014. From June 2014 to November 2015 He worked on European project NETMAR as postdoc engineer. Since 2017, he is Assistant Professor at Polydisciplinary faculty of Nador where he teaches electronic. His research interests include radar waves scattering, microwave remote sensing, electromagnetic wave propagation

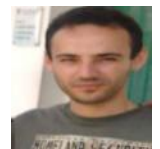

Ahmed Faize was born in Morocco in 1984.He holds a $\mathrm{PhD}$ from the University of Granada, Spain in the year 2012. Currently, he is a professor and researcher at Mohammed 1stUniversity, Faculty Polydisiplinarly, Nador and Head of Laboratory Applied Mathematics and Information Systems.

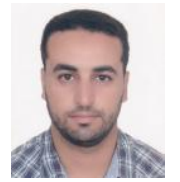

Mohammed HAMDAOUI was born in Oujda City, Morocco, in 1983. He obtained a B.S. in Experimental Sciences and a Master's degree in Electronics and Communication Systems at Mohamed I University, Faculty of Sciences, in Oujda. Currently works as a qualified graduate professor in Nador.

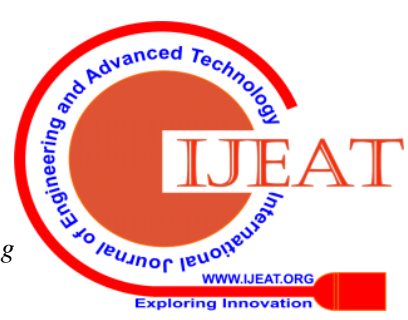

